\title{
Current Smoker
}

National Cancer Institute

\section{Source}

National Cancer Institute. Current Smoker. NCI Thesaurus. Code C67147.

An adult who has smoked 100 cigarettes in his or her lifetime and who currently smokes cig arettes. Includes daily smokers and non-daily smokers (also known as occasional smokers). 